\title{
A coprodução das ciências e das políticas na gestão da biodiversidade marinha brasileira: a controvérsia sobre o manejo sustentável de espécies ameaçadas
}

\author{
Andreza Martins ${ }^{2}$ \\ Julia Silvia Guivant ${ }^{3}$
}

\section{Resumo}

O uso sustentável de espécies ameaçadas está no centro de controvérsias tecnocientíficas internacionais que discutem o papel da ciência na orientação de políticas de conservação marinha. No Brasil, essas controvérsias repercutiram em disputas institucionais sobre a melhor forma de medir, avaliar e manejar os recursos pesqueiros. As disputas permearam negociações políticas para reversão de proibições de pesca de dezenas de espécies incluídas na Lista Nacional de Espécies Ameaçadas de Extinção. Sob a perspectiva dos Estudos Sociais da Ciência, discutimos a influência dos conhecimentos peritos nas negociações políticas implicadas no caso. Analisando argumentos de críticos e apoiadores da medida, compreendemos que, no Brasil, incertezas científicas sobre o estado de conservação da fauna aquática resultam em práticas de gestão pública divergentes atuando sobre os mesmos espaços e recursos. Tais práticas associam visões concorrentes sobre como a administração pública deve lidar com a incerteza científica e coproduzem políticas de gestão da biodiversidade marinha.

Palauras-chave: Estudos Sociais das Ciências. Ciência regulatória. Governança marinha. Coprodução.

I O presente artigo é baseado em pesquisa desenvolvida pela primeira autora, orientada pela segunda, no contexto da tese menor e foi realizado com apoio da Coordenação de Aperfeiçoamento de Pessoal de Nível Superior (Capes) - Brasil. Código de financiamento 001.

2 Pesquisadora Pós-doc. do Programa de Pós-Graduação em Sociologia Política da Universidade Federal de Santa Catarina (PPGSP/UFSC), Brasil. Integrante do Instituto de Pesquisa em Risco e Sustentabilidade da UFSC (IRIS/ UFSC). E-mail: andrezamartins@hotmail.com. ORCID: https://orcid.org/0000-000 I-6227-I920.

3 Professora Titular do Departamento de Sociologia e Ciência Política da UFSC, Florianópolis, SC, Brasil. E-mail: julia.guivant@ufsc.br. ORCID: https://orcid.org/0000-000I-620I-887X. atribua a autoria da obra, forneça um link para a licença, e indicar se foram feitas alterações. 


\section{Introdução}

Nas últimas décadas, diagnósticos e modelagens produzidos pela Organização das Nações Unidas para Alimentação e Agricultura (FAO) e União Internacional para Conservação da Natureza (IUCN) estão entre as referências mais utilizadas para avaliar o estado de conservação da biodiversidade marinha e direcionar políticas públicas de gestáo do uso sustentável dos recursos pesqueiros. Entretanto, o uso político desses relatórios é questionado por especialistas das ciências pesqueiras e da conservação, que criticam a fragilidade e superficialidade das avaliaçóes produzidas e sua eficácia na conservação marinha (COLLEN et al., 2016; CRESSEY, 2015; KAISER, 2013).

FAO e IUCN são agências internacionais que frequentemente atuam sobre os mesmos espaços e recursos ambientais, com objetivos, por vezes, divergentes. Enquanto a FAO trabalha para a promoção da pesca sustentável, a IUCN centra-se no estímulo à conservação marinha. Problemas emergem quando há sobreposição de áreas de atuação ou de objeto de gestão, a exemplo dos recursos pesqueiros. Neste caso, o debate especializado entra em ação e se subdivide em duas controvérsias tecnocientíficas internacionais que contestam a centralidade do emprego das diretrizes técnicas da FAO e IUCN no direcionamento de políticas de gestáo pesqueira e conservação marinha.

A primeira se dá majoritariamente entre peritos que integram os comitês de especialistas em conservação da IUCN e divergem sobre a aprovação do uso sustentável de espécies ameaçadas de extinção para fins comerciais. O principal vetor de discórdia aparece quando os dados sobre uma espécie são inconclusivos e reside na acusaçáo mútua entre os pares de que o posicionamento de seus opositores não está baseado nos dados, mas em ideologias (CAMPBELL; GODFREY, 2010; MROSOVSKY, 1997, 2000; RICHARDSON, 2000). Isto é, na presença de incerteza tecnocientífica, especialistas que discordam do uso sustentável de espécies ameaçadas acusam seus opositores de serem influenciados por grupos sociais beneficiários de tal liberação, enquanto cientistas propensos a discutir a prática acusam o outro grupo de se deixar influenciar por ONGs ambientalistas e náo considerar as necessidades de todas as coletividades humanas. 
$\mathrm{Na}$ segunda controvérsia, sobretudo cientistas pesqueiros discordam sobre a credibilidade dos dados empregados pela FAO para construir diagnósticos de saúde dos estoques. Em um grupo, alinham-se aqueles que defendem que os dados empregados pela agência são irreais ou insuficientes para a elaboração de diagnósticos. Como argumento, exploram a ausência de dados de monitoramento para a maior parte das unidades populacionais pesqueiras que não detêm significativo interesse econômico, inclusive nos países que melhor monitoram seus estoques. Para esses pesquisadores, o resultado dos diagnósticos da FAO, considerados por eles generalistas e superficiais, é o fortalecimento de um padrão de opinião que supóe que a única solução para a conservação marinha é a proibição das pescarias mundiais (BELHABIB et al., 2014, 2015; CHABOUD et al., 2015; WORM et al., 2009). Em outro grupo, posicionam-se aqueles que assumem que os dados empregados pela agência refletem de maneira geral o grau de abundância dos estoques, os quais devem, portanto, ser utilizados para subsidiar diagnósticos pesqueiros (BELHABIB et al., 2014; HALPERN et al., 2012; ROSENBERG et al., 2014). Para muitos desses pesquisadores, a maioria dos dados da FAO está inclusive subdimensionada e a situação dos estoques mundiais é ainda mais crítica do que a diagnosticada (CRESSEY, 2015; PAULY; ZELLER, 2016).

No Brasil, essas controvérsias repercutem de forma direta em disputas entre especialistas que mantêm posicionamentos divergentes sobre a melhor forma de medir, avaliar e manejar o peixe e a pesca e influenciam a formulação de políticas nacionais de conservação da biodiversidade marinha. Enquanto a maior parte dos cientistas pesqueiros defende o emprego de ferramentas técnicas das ciências pesqueiras, incluindo aquelas mobilizadas pela FAO, para nortear a gestáo pública da fauna marinha ameaçada (QUEIROZ et al., 2019; PIO; PEZZUTO; WAHRLICH, 2016; PATRI$\mathrm{CIO}$ et al., 2016), cientistas da conservação argumentam que as ferramentas da biologia e ecologia, a exemplo daquelas mobilizadas pela IUCN, são mais adequadas para a tarefa, particularmente quando existe algum grau de ameaça de extinçáo (MARRUL FILHO, 2003; DIAS NETO, 2015; RODRIGUES, 2006). Como nos debates internacionais, diferentes posicionamentos tecnocientíficos resultam em práticas políticas divergentes de gestão da fauna marinha. 
Contudo, ao contrário do que ocorre na maior parte das naçôes pesqueiras, no Brasil esses posicionamentos são operacionalizados em duas agências governamentais que atuam sobre os mesmos espaços e recursos, porém com objetivos de gestão incongruentes, a saber: o Ministério do Meio Ambiente (MMA), de caráter conservacionista, e o Ministério da Pesca e Aquicultura (MPA), de caráter desenvolvimentista. Até o ano de 2009, ambas as agências atuaram independentemente, criando diferentes normas, frequentemente conflitantes, para regulamentar a pesca e o manejo dos recursos pesqueiros. Entretanto, em outubro daquele ano, foi criado um Sistema (nacional) de Gestão Compartilhada do Uso Sustentável dos Recursos Pesqueiros (BRASIL, 2009), que exigia que MMA e MPA atuassem em conjunto e com paridade de responsabilidade institucional na definição e publicação de normas, critérios, padróes e medidas de ordenamento pesqueiro.

Durante seu período de vigência, embora duramente criticado por diferentes atores associados à pesca no país, esse sistema mantinha-se relativamente estável. A situaçáo começou a ser alterada em 20144 , com a publicação pelo MMA da Portaria MMA no 445/2014, que regulamentou a proibição de pesca e comercialização de 475 espécies incluídas na Lista Nacional Oficial das Espécies da Fauna Brasileira Ameaçada de Extinção - Peixes e Invertebrados Aquáticos (doravante Lista Vermelha Brasileira - LVB) (MMA, 2014). A Portaria no 445 é um instrumento de gestáo pública que se apoia em indicadores de conservação da IUCN para classificar o grau de ameaça de extinção da fauna aquática brasileira e estabelecer medidas nacionais de gestáo pesqueira sustentável. Sua publicaçáo gerou uma das maiores mobilizaçóes coletivas do setor produtivo da pesca da história do Brasil e deu início a uma série de processos jurídicos e disputas institucionais entre MMA e MPA pela obtenção da prioridade de regulamentação do manejo de espécies da fauna aquática enquadradas sob ameaça de extinção.

As tensóes e os conflitos gerados com a publicação dessa portaria implicaram diferentes grupos de atores (governamentais e não governamentais)

4 Em outubro de 2015, o MPA foi extinto e suas competências foram transferidas para o Ministério da Agricultura, Pecuária e Abastecimento (Mapa), que assume o ordenamento pesqueiro junto ao MMA. 
relacionados à pesca e à conservação marinha no Brasil em uma controvérsia tecnocientífica sobre a validade dos dados mobilizados pelo MMA para fundamentar proibiçóes de pesca. Enquanto o grupo de apoiadores da Portaria no 445 trabalhava junto ao MMA para a manutenção da vigência da norma, o grupo de críticos trabalhava em duas frentes concomitantes: i) negociando politicamente para obter a reavaliação do estado de conservação de espécies de interesse socioeconômico e, assim, obter algum tipo de flexibilização das proibiçóes de pesca; e ii) agindo judicialmente para sustar a norma.

A maioria dos argumentos e evidências técnicas empregadas no debate foi apresentada por pesquisadores especialistas das ciências pesqueiras e da conservação. Os argumentos de críticos da Portaria no 445 focaram, de forma preponderante, na (in)disponibilidade e incerteza dos dados científicos e na (ir)relevância dos critérios da IUCN para conservação de organismos aquáticos. $\mathrm{O}$ debate institucional implicou disputas acadêmicas sobre a melhor forma de avaliar o estado de conservação da biodiversidade marinha brasileira e, entre outros resultados importantes, culminou com o estabelecimento de um Grupo de Trabalho (GT) criado para reanalisar os dados publicados pelo MMA e reavaliar o status de conservação das espécies consideradas de relevante interesse socioeconômico.

Sob a perspectiva dos Estudos Sociais das Ciências (ESC), este artigo analisa a influência dos conhecimentos peritos mobilizados nos espaços de negociação e interface entre especialistas, agentes governamentais e demais atores implicados nas controvérsias originadas a partir da publicação da Portaria MMA no 445/2014. No âmbito dessa tradição de estudos, a socióloga Sheila Jasanoff nomina como "ciência regulatória" o domínio científico que opera na "zona social" de fronteira entre ciências e políticas, no qual um tipo de conhecimento técnico e científico particular é produzido com vistas a orientar a tomada de decisóes regulatórias. Nessa perspectiva, a noção de coprodução tem sido evocada para descrever o resultado do trabalho da ciência regulatória, um trabalho no qual se presume que ciências e políticas trabalham juntas para produzir realidades particulares (JASANOFF, 2011, p. 11). 
Na presente análise, as noções de ciência regulatória e coprodução são pertinentes para salientar dois elementos analíticos distintos que se justapôem e interagem nos cenários pesquisados: i) a noção de ciência regulatória destaca a existência de um lócus científico específico operando na zona social de interface entre as ciências e as polícias de conservação marinha e desenvolvimento pesqueiro; e ii) a noção de coprodução permite descrever o trabalho de cientistas regulatórios trabalhando nessa interface, na qual ciência e política produzem, juntas, realidades específicas.

Entender quais são e como foram validados e mobilizados os conhecimentos que embasaram diferentes posicionamentos políticos nos espaços de negociação e interface sobre o caso da Portaria MMA no 445/2014 representa a questáo central desta análise. Pretende-se demonstrar que existem diferentes definiçóes de verdade científica sobre a biodiversidade marinha no contexto brasileiro - definiçóes que envolvem visóes concorrentes sobre o papel e importância da fauna marinha para as coletividades humanas, que disputam pela definição de quem deve administrar e quais devem ser as ferramentas científicas e indicadores empregados para fundamentar a gestão do uso sustentável dos recursos pesqueiros no Brasil. Como verá o leitor, definiçóes de ciência boa e má e distinçóes imprecisas entre fatos e valores influenciam o enquadramento técnico das espécies em categorias de conservação com maior ou menor risco de extinção. No processo, controvérsias tecnocientíficas internacionais sobre o uso sustentável interagem com interesses privados e disputas de poder governamentais localizadas e coproduzem a Política Brasileira de Conservação e Uso Sustentável da Biodiversidade Marinha.

A análise está organizada em cinco partes, além desta introdução e das consideraçôes finais, com ênfase nos seguintes pontos: 1) controvérsia brasileira sobre a relação entre conservação marinha e uso sustentável implicada no caso da Portaria no 445; 2) procedimentos operacionais da pesquisa; 3) referencial teórico; 4) análise dos argumentos de críticos e apoiadores do uso da Portaria no 445/2014 e da LVB como instrumento de gestão pesqueira; e 5) coprodução da política brasileira de gestão do uso sustentável dos recursos pesqueiros. 


\section{Conservação ou uso sustentável? 0 caso da publicação da Portaria MMA n $445 / 2014$}

Em dezembro de 2014, o MMA publicou a Portaria no 445, que proíbe a captura, transporte, armazenamento, guarda e manejo de 475 espécies de organismos aquáticos listados na LVB (MMA, 2014). A medida deflagrou uma série de protestos do setor produtivo da pesca que aconteceram em diferentes pontos do país. Em 5 de janeiro de 2015, um desses protestos culminou com o impedimento do trânsito de embarcaçóes em um dos maiores portos pesqueiros do Brasil, o Porto de Itajaí, localizado no estado de Santa Catarina (SC). Imediatamente, os protestos ganharam destaque midiático, sobretudo devido ao bloqueio da partida de um transatlântico que transportava cerca de 2.400 pessoas em um cruzeiro de luxo até Buenos Aires, Argentina. Todas essas pessoas ficaram presas no porto sem permissão para desembarcar durante 24 horas. Após sua liberação, o cruzeiro teve a rota alterada e dezenas de pessoas desistiram de zarpar, exigindo ressarcimento de despesas. A empresa responsável pelo cruzeiro alegou prejuízos consideráveis (JORNAL NACIONAL, 2015; APÓS 30 HORAS..., 2015).

Os manifestantes, liderados pelas principais entidades patronais da pesca industrial, solicitavam a anulação da Portaria no 445 , por prejudicar o setor que emprega, segundo eles, aproximadamente 50 mil pessoas em Santa Catarina e produz cerca de $25 \%$ do pescado in natura e $80 \%$ do pescado congelado consumido nacionalmente. Segundo o então presidente do Sindicato das Indústrias e Armadores de Pesca de Itajaí e Regiáo (Sindipi), uma das lideranças dos protestos, a Portaria comprometia 50\% do volume de pesca no litoral norte de Santa Catarina, maior polo pesqueiro industrial brasileiro (GUERRA, 2015). O MMA contra-argumentou alegando que somente 79 das espécies da LVB possuem valor comercial, sendo que 33 delas são categorizadas como "vulneráveis" e podem ser capturadas desde que respeitem planos de gestão específicos elaborados por agências competentes (LISTAS NACIONAIS..., 2014).Apoiado por alguns pesquisadores e pelo MPA, o segmento produtivo contestou as avaliaçóes do MMA alegando serem insuficientes e não refletirem a realidade da abundância dos estoques pesqueiros nacionais (NEVES, 2015). Em resposta, o 
MMA defendeu o rigor tecnocientífico das pesquisas. Em evento promovido pelo Sindipi ${ }^{5}$, a representante do Instituto Chico Mendes de Conservação da Biodiversidade (ICMBio), autarquia do MMA responsável pela elaboração da LVB, explicou que a lista foi construída com base nos critérios globais de conservação da IUCN (2001) e em estudos locais realizados por pesquisadores do próprio MMA e cientistas colaboradores. Criticando a exclusividade do emprego de dados secundários nas avaliaçóes, o presidente do Sindipi utilizou o seguinte contra-argumento: "Questionamos toda a lista. [...] as pesquisas foram feitas dentro do escritório, queremos que a pesquisa seja feita com os recursos abundantes no mar." (CALGARO, 2015).

O MPA solicitou ao MMA a reavaliação das espécies consideradas de interesse comercial, alegando a necessidade de adequação de medidas que considerassem as necessidades econômicas e sociais do setor pesqueiro. O MMA cedeu às pressóes e constituiu um GT Interministerial para reavaliar o status de conservaçáo de algumas espécies. Paralelamente, o MPA criou um GT Técnico (GTT) composto por representantes do segmento produtivo pesqueiro (industrial e artesanal), segmento aquícola, empresas de aquarismo e cientistas pesqueiros, para revisar as avaliaçóes do MMA e subsidiar as açóes dos representantes do MPA no GT Interministerial. Em meio aos debates no GT Interministerial, o MMA adiou duas vezes a entrada em vigor da portaria. Concomitantemente, as principais entidades patronais da pesca do país, em parceria com a Federação Nacional dos Engenheiros de Pesca do Brasil, entraram com ação no Tribunal Regional Federal da Primeira Região (TRF1) contra a Uniāo, solicitando a anulação da portaria sob alegaçáo de que não poderia ter sido publicada de forma unilateral pelo MMA. Em junho de 2015, o desembargador responsável pelo caso sustou a norma, acatando o argumento dessas organizaçóes (ECODEBATE, 2015).

A decisão se baseou na interpretação da legislação brasileira em vigor para o gerenciamento público dos recursos pesqueiros. Até dezembro de 2019, esses recursos eram geridos pelo Sistema de Gestão Compartilhada do Uso Sustentável dos Recursos Pesqueiros (doravante SGC) entre MMA

5 Seminário Novos Rumos para Pesca Industrial, organizado por Sindipi em 24 de junho de 2015. 
e agências públicas responsáveis pelo ordenamento da pesca e aquicultura ${ }^{6}$. Até outubro de 2015, essa competência administrativa cabia ao $\mathrm{MPA}^{7}$. O SGC definia como responsabilidade do MMA defender a conservação dos recursos pesqueiros avaliados como sobrexplotados ou em vias de sobrexplotação ${ }^{8}$, evitando pressão sobre os estoques. Ao MPA cabia promover açóes de fomento à pesca, ordenar os recursos considerados subexplotados ou inexplotados e coordenar o SGC (BRASIL, 2009). Como o MPA não foi consultado sobre a edição da norma, o desembargador entendeu que houve uma sobreposição de competências administrativas e sustou-a (PRESOTTI, 2015). Desde então, a 445 é alvo de sucessivos recursos em diferentes instâncias judiciais, movidos por apoiadores e críticos ao emprego da norma como instrumento público de gestão pesqueira.

Em paralelo às disputas judiciais, os principais atores implicados seguem as negociaçôes nas instâncias governamentais, conforme demonstram as transmissóes ao vivo das reuniōes oficiais do GT Portaria 445, disponibilizadas no canal do YouTube da ONG Oceana Brasil (REUNIÓES GT 445, 201-). Esse GT foi criado em maio de 2017, pelo MMA, com o propósito de reavaliar e recomendar açóes de conservação e uso sustentável para algumas espécies identificadas como de interesse socioeconômico. No primeiro semestre desse mesmo ano, foram publicadas, pelo MMA, duas outras portarias (MMA no 161/2017 e MMA no 217/2017), que novamente estenderam os prazos para entrada em vigor das proibiçóes de pesca para algumas espécies (Figura 1).

6 Em janeiro de 2019, o SGC é extinto e o Mapa, por intermédio da Secretaria de Aquicultura e Pesca, passa a deter a exclusividade da competência de regulamentar a Política Nacional de Desenvolvimento Sustentável da Aquicultura e da Pesca (PNDSAP).

7 Após a extinção do MPA, as competências relativas às agências pesqueiras passam para o Mapa, mas em novembro de 2017 migram para a administração da Secretaria Especial de Aquicultura e Pesca, uma autarquia ligada à Presidência da República do Brasil.

8 Terminologia empregada nos documentos do Ibama para fazer referência à biologia e ecologia dos estoques marinhos (BRASIL, 2005). 


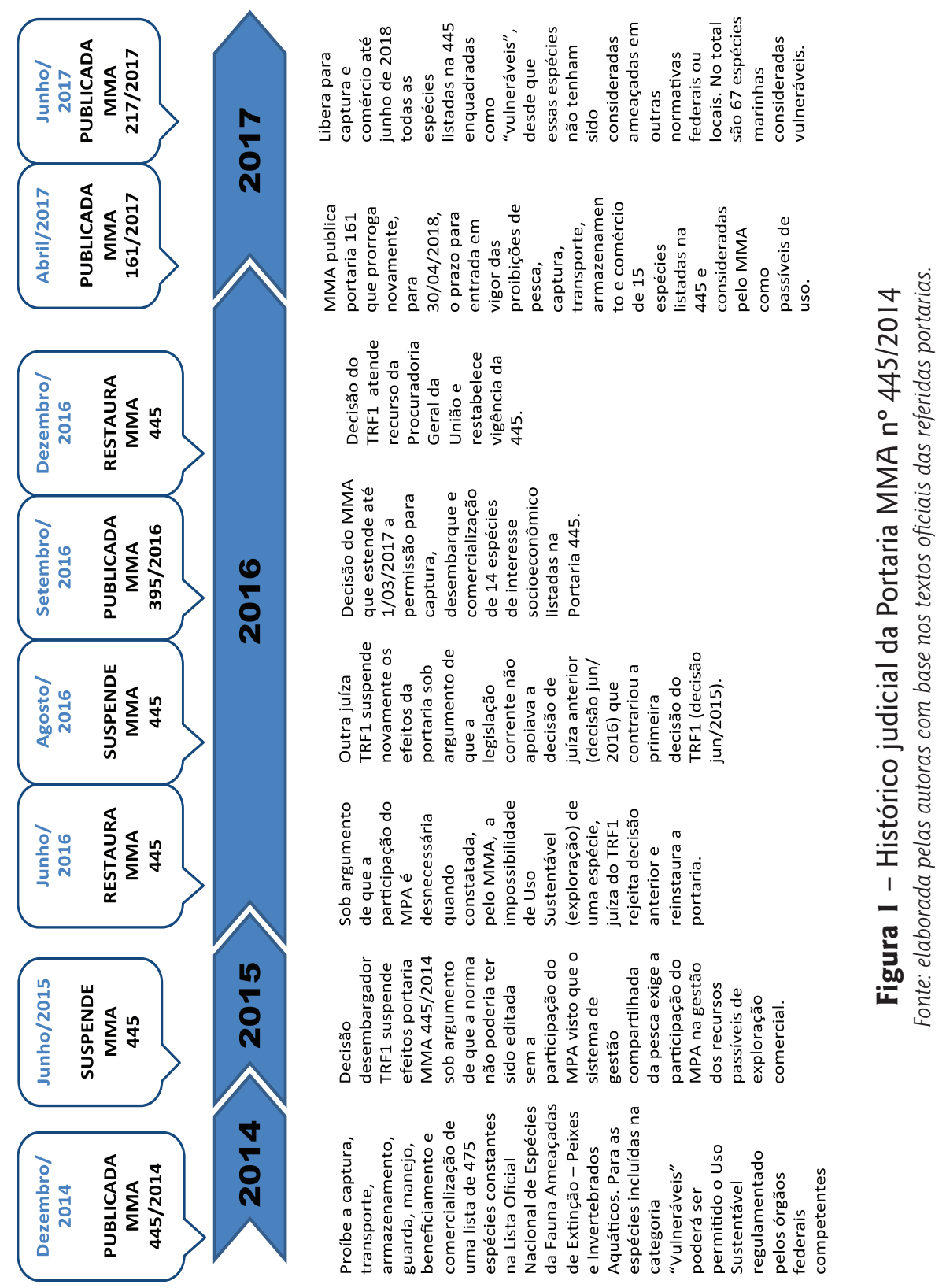




\section{Métodos}

Vinte e dois informantes foram entrevistados entre junho de 2015 e dezembro de 2016, incluindo: i) formuladores de políticas, gestores e funcionários especialistas em conservação marinha e gestão pesqueira do MMA e do MPA que participaram do processo de elaboração da Portaria MMA no 445/2014 ou dos debates institucionais que a sucederam; ii) consultores ad hoc integrantes do GT Interministerial e GTT do MPA; iii) integrantes da diretoria dos principais sindicatos patronais da pesca do Brasil; e vi) pesquisadores e técnicos em conservação marinha, biologia, oceanografia e engenharia de pesca integrantes de comitês nacionais e internacionais e GTs estratégicos criados para subsidiar políticas de gestão pesqueira e conservação marinha nos oceanos Atlântico e Pacífico, entre outros.

A análise está fundamentada em 25 entrevistas presenciais (alguns informantes foram arguidos em mais de uma ocasião) realizadas no Brasil e na Europa (região da Galícia/Espanha e no sul da França). A seleção dos entrevistados foi baseada em diferentes critérios, com destaque para: i) grau de protagonismo e experiência administrativa nas agências públicas federais de gestáo pesqueira e/ou conservação marinha; ii) participação no processo de elaboraçáo da Portaria no 445 e/ou nos debates institucionais que a sucederam; iii) experiência em pesquisa pesqueira e/ou biologia marinha no cenário brasileiro e/ou da União Europeia; e iv) conhecimento dos mercados de comércio de pescados de origem extrativa.

Entre dezembro de 2014 (data de publicação da Portaria no 445) e outubro de 2018 (encerramento da análise), a pesquisa também analisou numeroso material midiático (imprensa impressa, digital e televisa) sobre o bloqueio do transatlântico no Porto de Itajaí e sobre os conflitos judiciais e institucionais originados com a publicação da Portaria no 445/2014. Dados documentais, impressos e disponíveis ao público ou cedidos pelos entrevistados, processos judiciais relacionados ao caso da Portaria $\mathrm{n}^{\mathrm{o}}$ 445 e disponíveis nos portais públicos de serviços judiciários dos estados de Santa Catarina e Rio Grande do Sul e do Distrito Federal e material de divulgação oficial de agências governamentais, sindicatos e empresas do segmento pesqueiro também integraram o conjunto de evidências que 
subsidiou a elaboração deste artigo. Para a organização e codificação dos dados, foi utilizado o software de análise qualitativa MAXQDA12.

\section{Coprodução, controvérsias e ciência regulatória: a interface terra-mar em perspectiva}

No que se refere à temática da gestão pública ambiental, a chave conceitual de alguns dos trabalhos dos Estudos Sociais da Ciência centra-se sobre o problema de conhecer a natureza. $\mathrm{Na}$ opinião do sociólogo Alan Irwin (2008), ciência e tecnologia são valiosas para a gestão ambiental precisamente porque oferecem formas particulares, autônomas, distantes e poderosas de compreender a natureza. Já para o sociólogo Steven Yearley (2008), a contribuição distintiva dos Estudos Sociais da Ciência para a gestão ambiental assenta-se na demonstração de que a própria prática de conhecer a natureza molda e direciona o conhecimento que dela resulta e isso influencia decisivamente seus efeitos sobre os atores e as práticas que mobilizam esses conhecimentos.

Nesta pesquisa, a perspectiva ofertada pelos ESC merece nossa atenção por duas particularidades teóricas: 1) a contestação da separação entre ciência e tecnologia, tratadas neste enfoque como tecnociência; e 2) o questionamento da cisáo entre ciência e política. No primeiro caso, presume-se que a produção e a circulação de fatos e artefatos (técnicos) estáo entrelaçadas e, sendo assim, não podem ser analisadas separadamente. A noção de tecnociência é assim tomada como um conceito pertinente para analisar como práticas científicas e tecnológicas estão associadas e quais são seus efeitos sob a geração das realidades investigadas. A crise global dos estoques pesqueiros é um exemplo interessante de problema ambiental em que diferentes fatos e artefatos estáo atuando para criar, publicizar e manter $\mathrm{o}$ argumento da crise em circulação.

Nesse sentido, tecnociência e sociedades são vistas como portadoras de uma natureza coproduzida. A noção de coprodução envolve o entendimento de que "as realidades da experiência humana emergem como as realizaçóes conjuntas de empreendimentos científicos, técnicos e sociais: a ciência e a sociedade, em uma palavra, são coproduzidas, cada uma subsidiando a existência da outra" (JASANOFF, 2004, p. 17). O emprego dos 
termos "tecnociência" e "sociotécnico", portanto, não é ao acaso, mas uma opção consciente para grifar a natureza "coproduzida" (JASANOFF, 2004) da ciência, tecnologia e sociedades (LATOUR; WOOLGAR, 1997; LAW; SINGLETON, 2000). Assim, uma questão central diz respeito à relação entre a tecnociência, o poder político e a açáo institucional (IRWIN, 2008; SISMONDO, 2008). Desafiando a suposição convencional de que o problema da administração da tecnociência se resume a comunicar a "verdade" às instituiçốes de poder (HAAS; JASANOFF, 2004; IRWIN, 2008; MOL, 1999), alguns estudos levantaram questóes fundamentais sobre a forma como os resultados tecnocientíficos são apresentados e enquadrados, por que alguns resultados ganham mais destaque do que outros e quais os pressupostos culturais frequentemente implícitos nesses enquadramentos e decisões (HACKETT et al., 2008). A abordagem contesta o pressuposto tradicional que presume que "tecnociência" e "política" podem ser diretamente identificadas, depuradas e demarcadas. Ao contrário, considera-se que a própria identificação e demarcação de fronteiras entre mundos identificados como "científicos", "tecnológicos" ou "políticos" representa um elemento-chave para ser questionado (IRWIN, 2008).

No que se refere às ferramentas analíticas empregadas para investigar os espaços sociais de interface entre tecnociência e política, o livro The Fifth Branch: Science Advisers and Policymakers, de Sheila Jasanoff, emprega, de forma pioneira, o termo "ciência regulatória" para descrever uma área específica da atividade científica na qual um tipo de conhecimento tecnocientífico particular é produzido com vistas a orientar a tomada de decisôes regulatórias e promover a formulação de políticas. Jasanoff inaugurou, dentro dos ESC, uma linha de estudos dedicada a investigar como fatos são fabricados e produzidos nesse domínio de atividade científica que serve às políticas públicas. $\mathrm{O}$ propósito era compreender por que processos regulatórios comprometidos com a tomada de decisão racional a partir da aplicação do conhecimento científico falhavam, com frequência, em produzir consensos (JASANOFF, 2011)Jasanoff first proposed the concept of regulatory science in an analytical way, though there may be some isolated mentions before; (2. Suas análises demonstraram que a função de cientistas consultores de políticas (cientistas regulatórios) emerge de um conjunto particular de discussóes dependente do contexto que difere do contexto 
em que é produzida a ciência de pesquisa laboratorial, por exemplo. Para Jasanoff, cientistas regulatórios têm responsabilidades e objetivos claros definidos pelas políticas que necessitam informar. Sua prática envolve um trabalho de fronteira entre ciência e política em que aquilo que pertence ao lado científico da fronteira não é conhecido de antemão. $O$ resultado desse trabalho é, portanto, coproduzido (JASANOFF, 2011)Jasanoff first proposed the concept of regulatory science in an analytical way, though there may be some isolated mentions before; $(2$.

A ciência regulatória, nesse sentido, não está separada da política nem é uma fonte de verdade objetiva externa capaz de solucionar os problemas da política. Em vez disso, "estados particulares de conhecimento são alcançados e mantidos em circulação, ou abandonados" (JASANOFF, 2011, p. 19). Assim, em vez de ater-se à busca de verdades absolutas e incontestes, a questáo da ciência regulatória, na avaliação dessa autora, está associada à definição do que será considerado como objetivo ou verdadeiro e de quem participa dessas definiçóes. Diferente de outros campos da ciência, a de caráter regulatório não opera sob a égide de verdades absolutas, mas sob o horizonte das "verdades úteis" que não são absolutas nem eternas, mas adequadas para prosseguir e fazer política para o propósito preestabelecido (JASANOFF, 2011, p. 9). Para autora, o mundo da política já trabalha com essas verdades; é preciso, no entanto, que isso seja assumido também pelos cientistas.

A definição dos propósitos das políticas é outra questão-chave da ciência regulatória. Nem sempre eles são explícitos ou predeterminados e, nessas situaçóes, as controvérsias se avolumam. Abrem-se precedentes para debater quais são os propósitos adequados. Este é o caso dos debates sobre a melhor forma de gestão pública da fauna marinha extrativa de interesse socioeconômico no Brasil. Não há opção política clara por um ou outro modelo de gestáo. Como se verá, há uma tensão entre especialistas da conservação e da pesca (funcionários governamentais e outros), que defendem diferentes técnicas para medir e avaliar o estado de conservação dos organismos aquáticos. Técnicas diferentes usam indicadores diferentes, que levam a diferentes interpretaçóes de estado de conservação e a diferentes orientaçôes de gestão. Questôes aparentemente técnicas estão ligadas a ideias concorrentes de como a biodiversidade marinha deve ser manejada. 
Por resultarem de negociaçóes processadas em cenários politizados, os resultados do conhecimento produzido nessa zona de fronteira entre ciência e política tendem a ser controversos (SALTER; LEVY; LEISS, 1988; TURNER, 2001). Por controvérsia, entende-se aqui uma situação de conflito no interior da qual diferentes atores discordam em diversas questóes relativas a um ou mais problemas (LATOUR, 2011).

A noção de controvérsia é particularmente adequada para apreender e depurar a existência de diferentes posicionamentos, interesses e valores atuando nos debates acadêmicos e institucionais que entrecruzam políticas de gestão pesqueira e conservação marinha. Ela nos permite indagar sobre quais são os conhecimentos em jogo nas arenas políticas que mobilizam diferentes argumentos tecnocientíficos para fundamentar posiçóes pessoais ou de interesses privados. Investigar a tecnociência em ação na construção de dados e alegaçóes sobre o estado de conservaçáo da fauna marinha de interesse socieconômico e as possibilidades de manejo para fins comerciais ajuda a depurar o emaranhado de informaçóes, atores, interesses e espaços implicados na controvérsia institucional entre diferentes posiçóes sobre conservação marinha e gestão pesqueira no Brasil.

De fato, um dos primeiros focos de inquérito dos ESC foi a questão das controvérsias tecnocientíficas (LATOUR; WOOLGAR, 1997; NELKIN, 1980). Para Jasanoff (2013), "se a ciência é a melhor aproximação que temos da realidade, então ela deveria acabar com as controvérsias e não prolongá-las". Contudo, em uma ampla faixa de questôes sociais, a exemplo do meio ambiente, saúde, nutrição, entre outras, a ciência parece mais frequentemente servir como um atrator para divergências. A explicação fácil é que isso acontece porque os cientistas são capturados por interesses pessoais e/ou políticos. Dessa premissa, segue-se que a solução é erigir barreiras em torno da ciência, protegendo-a de influências corruptoras. Contudo, os ESC chegaram a uma conclusão oposta. Em situaçóes de interface, a comunicação e a confiança entre ciência e política devem ser radicalizadas e cabe aos cientistas relacionarem-se com a política de formas mais inteligentes (IRWIN, 2008; JASANOFF, 2013).

Para o caso da ciência regulatória, Jasanoff (2013) lista as principais descobertas que justificam essas alegaçóes: 1) a ciência regulatória é a 
principal saída para processos consultivos que são carregados de valor. Juízos de valor definem quais fatos e disciplinas devem participar dos comitês consultivos, quando novos conhecimentos são confiáveis o suficiente para serem utilizados, que pontos de vista divergentes seráo considerados e quando a ação é apropriada. O problema decorrente é como gerenciar a função de fronteira, isto é, manter a relevância e confiança, sem comprometer a integridade científica; 2) nenhuma parte da ciência regulatória é independente de lei, política e valores. É importante que cientistas regulatórios aceitem isso, particularmente para entenderem quando há recusa pública dos seus conselhos. Muitas das críticas à ciência regulatória não são dirigidas aos dados usados para defender uma ou outra posição, mas ao fracasso dos cientistas em incluir como variável analítica a previsão de problemas de responsabilidade decorrentes de resoluções políticas tomadas sob aconselhamento científico. Neste caso, cientistas podem argumentar que não são responsáveis pelos resultados de seus aconselhamentos e que só lhes importa o que os dados informam. Entretanto, o público tem boas razóes para supor que especialistas levaráo em consideração os riscos e questóes de segurança pública, bem como os interesses em jogo no aconselhamento científico; 3) cientistas regulatórios geralmente acompanham promessas e práticas da ciência de pesquisa "normal" atribuindo valor desproporcional àquilo que já é conhecido e está bem estabelecido. $\mathrm{O}$ que não está bem estudado ou livre de escrutínio tende a ser deixado de fora da consciência imediata dos demais conselheiros. Essa tendência leva, por sua vez, a uma relativa desaprovação de evidências sociais e comportamentais difíceis de coletar, em comparação com fatos mensuráveis sobre o mundo natural; e 4) cientistas regulatórios participam e tendem a reproduzir características culturais marcantes de uma nação ou regiáo, incluindo o julgamento de valor sobre o conhecimento técnico (melhor ou pior, menos ou mais interessado etc.), integridade e experiência pessoal e engajamento em pontos de vista significativos das sociedades de sua referência. Essas preferências culturais, frequentemente ocultas, podem afetar o equilíbrio de um sistema consultivo e a capacidade de aprender com erros do passado.

Diante do exposto, se partirmos do pressuposto de que a conservação marinha e a gestão pesqueira são realidades coproduzidas, isto é, organizadas a partir e durante as práticas de diferentes atores (cientistas, políticos, 
técnicos, empresários, pescadores etc.) que nelas estão implicados, e que essa coprodução gera diferentes realidades atuando simultaneamente sobre o mesmo objeto, neste caso o mar e os peixes, entáo interessa investigar como, por quem e que tipo de realidades de conservação marinha e gestão pesqueira estão sendo coproduzidas nas redes de atores implicados na controvérsia sociotécnica sobre a gestão pesqueira marinha no Brasil. De forma adicional, entender que os processos de gestáo pública ambiental e pesqueira são diretamente influenciados por informaçôes tecnocientíficas produzidas a partir de parâmetros e modelagens que não são neutros e despolitizados, possibilita trazer à tona as relaçóes de poder que estấo por trás ou "no meio" dos debates sobre gestâo ambiental pesqueira. O enquadramento teórico dos ESC nos permite entender que existem diferentes posiçóes neste debate e que as que estão em evidência, o estão por alguma razão.

\section{Resultados}

Tensôes e disputas entre agências governamentais ambientais e de desenvolvimento pesqueiro têm sido uma constante na história dos sistemas institucionais brasileiros de gestão pesqueira (DIAS NETO, 2015; MARRUL FILHO, 2003; PAIVA, 2004). Entre outras influências, disputas travadas no interior e entre instituiçóes públicas de gestão ambiental e pesqueira refletem dilemas teóricos de governança sobre conservação marinha e pesca sustentável. A própria criação no Brasil do Sistema de Gestão Compartilhada da Pesca reflete essas preocupaçóes, na medida em que implica duas entidades públicas com objetivos de gestão divergentes atuando sobre o mesmo objeto.

Os conflitos institucionais que se desprendem da publicação da Portaria no 445 estão imersos, portanto, em agendas teóricas que discutem a conservação em contraponto ao uso sustentável da biodiversidade marinha e delas procedem. São esses conflitos que serão discutidos a seguir, ao analisar os argumentos de críticos e apoiadores do uso da Lista Nacional Oficial de Espécies da Fauna Ameaçadas de Extinçáo - Peixes e Invertebrados Aquáticos para fundamentar políticas de gestão da pesca. O propósito é compreender como debates teóricos sobre conservação marinha e uso 
sustentável influenciaram as negociações governamentais sobre a regulação do ordenamento pesqueiro no Brasil.

\section{Ciências da conservação e ciências pesqueiras: com quem fica a espada da ciência?}

No que se refere à produção de informações nacionais em ciência pesqueira e biologia marinha, tanto documentos anexados aos processos jurídicos movidos pelo segmento pesqueiro quanto depoimentos publicados na imprensa e entrevistas realizadas no quadro desta pesquisa evidenciam a descrença do segmento produtivo e parcela do acadêmico ligado à pesca sobre os dados utilizados pelo MMA para embasar as proibiçóes listadas na Portaria no 445 . A principal alegação é que as análises são insuficientes e náo refletem a realidade da abundância dos estoques nacionais.

Independente de concordarem ou não com os argumentos do segmento produtivo, são consensuais entre críticos e defensores da portaria a fragilidade do cenário informacional pesqueiro brasileiro e os problemas que isso representa para a gestão pública da biodiversidade aquática. Em janeiro de 2015, logo após a publicação da portaria, um grupo de 19 instituiçóes de pesquisa e 30 especialistas renomados liderados pela ONG Oceana Brasil encaminhou à entáo presidenta da República um documento intitulado "Carta Aberta à Presidenta Dilma Roussef", que, entre outras reivindicaçôes, demandava o estabelecimento de "uma política pesqueira qualificada baseada em dados e diagnósticos confiáveis", considerados por esses atores a base para a gestão do uso sustentável (CARTA ABERTA..., 2015).

Outro argumento mobilizado, sobretudo por cientistas pesqueiros conselheiros do MPA nas negociaçóes do GT Interministerial, contestava a legitimidade das modelagens e indicadores empregados pela IUCN para avaliar espécies aquáticas. Para eles, as modelagens da IUCN foram elaboradas para investigar espécies terrestres e direcionar políticas públicas de conservação em terra e, portanto, eram inadequadas para analisar espécies aquáticas. Em sua avaliaçáa, as modelagens da IUCN refletem indicadores das ciências da conservação que são muito restritivos, com tendência para enquadrar as espécies em categorias de conservação nas quais a legislação 
A coprodução das ciências e das políticas na gestão da biodiversidade marinha brasileira: a controvérsia sobre o manejo sustentável de espécies ameaçadas | Andreza Martins, Julia Silvia Guivant

brasileira não permite nem mesmo o uso sustentável. $\mathrm{O}$ depoimento de um cientista pesqueiro brasileiro, especialista em avaliaçóes de estoques na interação com a pesca extrativa industrial e ex-gestor do MPA, detalha o argumento:

São visões diferentes porque a IUCN, por exemplo, diz que uma redução populacional de $30 \%$ em relação à população original da espécie, dependendo da característica do ciclo de vida, já passa a ser vulnerável, e vulnerável, pela legislação brasileira, já é ameaçada de extinção. Já não pode pescar. Sob ponto de vista da dinâmica populacional das espécies-alvo da pesca, 30\% eu ainda não atingi o máximo rendimento sustentável. Ou seja, são duas ciências completamente diferentes. Agora quem deveria estar na frente na ciência pesqueira é a ciência pesqueira. [...] Então é nesse sentido que eu digo que parece que a questão ambiental não conversa com a questão pesqueira, porque são duas linhas de visão, na verdade duas linhas filosóficas diferentes. (E19, 16 set. 2016).

Os especialistas em fauna marinha do ICMBio/MMA se defendem acusando os cientistas pesqueiros de incorrerem no mesmo erro que criticam, ou seja, de se apoiarem em modelagens imprecisas e baseadas em inferências que não refletem com precisão a abundância dos estoques no mar. $\mathrm{O}$ depoimento de um dos técnicos que integraram a linha de frente do processo de elaboração da LVB, bem como as negociações entre MPA e MMA, explicita o argumento:

A metodologia da IUCN é confiável porque ela simplesmente te dá limiares. A metodologia de avaliação de estoque, que tanto defenderam ai, ela faz isso também, ela te dá limiares. Ela te diz o seguinte: alguns modelos de produção dizem que, se tu tiveres explorando o estoque até $50 \%$ da biomassa desovante, tá tranquilo. Agora, quem disse que aquele teu modelo, com certeza, te garante que você está realmente explorando 50\%? (EI4, 16 ago. 2016).

Quando confrontados com a resposta dos especialistas do MMA, cientistas pesqueiros entrevistados tenderam a redirecionar a crítica para o problema da responsabilidade social. Para eles, as listas da IUCN são elaboradas por especialistas da biologia e ecologia das espécies que não consideram as variáveis socioeconômicas na elaboração de recomendaçóes finais:

E o que existe hoje, pelo histórico que eu te contei do que o MMA fez ou deixou de fazer, não tinha mais o componente da ciência pesqueira atuando no cenário, fazendo contraponto. Ou seja, a visão conservacionista, ela tomou espaço. Tomou espaço inclusive no 
sentido de dizer assim, eu tenho que proteger o meio ambiente e se a pesca não está sendo bem gerenciada, então eu tenho que considerar a proteção das espécies em primeiro lugar. A proteção do meio ambiente. E isso que aconteceu. Então existe um desbalanço aí. (EI9, 16 set. 2016).

$\mathrm{Na}$ concepção deste cientista entrevistado, as modelagens das ciências pesqueiras sáo mais adequadas para avaliaçáo de espécies de interesse comercial porque consideram ambos os parâmetros, isto é, a conservação das espécies e as variáveis socioeconômicas. Cientistas da conservação se defendem dizendo que as modelagens tradicionalmente empregadas pelas ciências pesqueiras para medir o limite máximo que um estoque suporta ser capturado sem prejudicar sua taxa de reposição natural - Rendimento Máximo Sustentável (RMS) - são tendenciosas porque priorizam a conservaçáo de espécies de interesse comercial em detrimento de outras espécies ameaçadas que, rotineiramente, são capturadas junto com as espécies-alvo das pescarias. Este é o argumento de um técnico do ICMBio, especialista em pesca e conservação marinha:

[Então quando se tem uma pescaria pouco seletiva, o ICMBio calcula o RMS pela espécie que está mais ameaçada?] Sem dúvida nenhuma. Aí é onde eu queria chegar, no sentido de... eu, na minha visão, ai é que me parece que está o problema. Não só da discordância entre metodologias, e nem sempre ela é uma discussão objetiva, né, que chegue nisso. [...] [Por que então fica o pessoal do ICMBio querendo calcular o RMS por espécies ameaçadas e o pessoal da pesca querendo calcular pelas espécies-alvo?] Isso, então esse é, acho eu, o ponto G. Pronto, esse é o ponto. (EI7, 29 ago. 2016, questões de uma das autoras entre colchetes).

Ao expressar sua opiniáo sobre o que considera ser o real motivo de divergências entre segmento pesqueiro e conservacionistas, este entrevistado distingue, de forma explícita, ciência e interesses. Para ele, o que está em jogo não é a definição do melhor modelo para avaliar as espécies, mas quais espécies devem ser avaliadas (e conservadas) e quais devem ser ignoradas na definição de medidas regulatórias para pesca. A explicação remete a divergências de fundo entre cientistas da conservação e pesqueiros. Enquanto os primeiros trabalham com práticas balizadas por parâmetros ecológicos, que priorizam a preservação das espécies ameaçadas, as práticas dos segundos são pautadas na manutenção das espécies de interesse comercial. 
Em nenhum momento, os críticos da Portaria no 445 se opuseram à avaliação das espécies. As críticas foram todas voltadas para a modelagem da IUCN e para a qualidade das avaliaçóes (dados incertos e insuficientes), mas não houve menção contrária à execução de avaliaçôes. $\mathrm{O}$ teor das críticas foi explícito e enquadrado em termos tecnocientíficos. Este também foi o foco das práticas dos não especialistas opositores da portaria. Uma das principais açóes executadas após a última decisão do TRF1 consistiu em estabelecer uma série de acordos com o MMA para o adiamento do início da vigência das proibiçóes de pesca para 15 espécies de interesse socioeconômico. Conforme menção anterior, duas novas portarias foram editadas pelo MMA, adiando o início das proibiçóes. A Portaria MMA no $217 / 2017$ prorrogou para junho de 2018 o início das proibiçóes de pesca para essas 15 espécies.

Sobre este último acordo, o setor pesqueiro industrial protocolou uma carta na sede do MMA, na qual solicita a reclassificação de algumas espécies da categoria "vulnerável" para "sobrexplotadas" ou "ameaçadas de sobrexplotação". As espécies listadas na primeira classificação necessitam de planos de recuperação elaborados pelo MMA para serem liberadas para pesca, já aquelas enquadradas nas duas últimas podem ser capturadas porque não entram na Portaria no 445 . Sobre esse tema, o diretor do Departamento de Conservação e Manejo de Espécies do MMA afirmou:

Considerando que algumas espécies foram identificadas como sendo passíveis de uso e que a orientação para a sua conservação remete ao uso sustentável, o ministério resolveu, então, publicar essa nova portaria que dá mais um ano para que sejam estabelecidas, de forma estruturada, as medidas para o manejo sustentável. (PROIBIÇÃO DE PESCA, 20।7).

Associado a este, existe um questionamento do valor normativo dessas avaliaçôes para a conservação da biodiversidade marinha per se. A crítica é formulada dentro do próprio MMA. De acordo com entrevistados do ICMBio, havia muitos técnicos contrários ao uso da LVB para definir medidas de gestão de pesca extrativa.

Porque assim, deixa eu separar bem as coisas. Não é, não publiquem a portaria de espécies ameaçadas, ninguém diria isso [...]. É, ao publicar a portaria de espécies ameaçadas, publiquem só a portaria de espécies ameaçadas, é isso. E não um penduricalho de desdobramentos e penalidades a partir dela, porque, principalmente pra pesca. Porque foi aí 
que o setor ganhou a liminar [...] E foi assumido então de certa maneira, porque o $M M A$ concordou, criou um GT, então houve um passo pra trás do MMA. Porque lá dentro já era discutido isso. Porque já havia alertas. [...] quando você vai além da lista de espécies, cria condicionantes e situações onde você não teria e não tem até hoje a estrutura governamental pra fazer tudo aquilo acontecer, você criou um gap, uma situação irreal. Então ficou uma situação muito ruim. (E17, 23 ago. 2016).

$\mathrm{O}$ argumento aqui analisado está associado a um questionamento de ordem estrutural sobre a capacidade da agência ambiental de gerenciar as práticas administrativas impostas pela portaria que ela mesma criou. $\mathrm{Na}$ avaliação do entrevistado, açóes desse tipo não resolvem o problema da sobrepesca e ainda ampliam o abismo entre as agências ambientais e os pescadores, o que, em sua avaliação, inevitavelmente dificulta a conservação marinha.

\section{Entre ciências e políticas de gestão da biodiversidade marinha}

Independente do nível de escolaridade e do segmento que representam, tanto críticos quanto apoiadores da Portaria no 445 associam seus argumentos à credibilidade tecnocientífica e aos interesses daqueles que discordam deles. Enquanto integrantes do MMA e apoiadores defendem as metodologias do MMA e recriminam os críticos, nem sempre de forma explícita, por estarem interessados no comércio dos pescados, os críticos atacam essas metodologias e afirmam que os apoiadores não pensam nos pescadores e só se interessam pelo meio ambiente. Embora os argumentos mobilizados por ambos sejam cientificamente enquadrados, discursos e açóes sáo apoiados em interesses e julgamentos de valor. A linha entre ciência e política é, portanto, obscurecida.

Adicionalmente, não é possível rastrear onde começam e terminam argumentos de cientistas da conservação e pesqueiros nas sucessivas decisôes do MMA de adiar a vigência de proibição das pescarias sobre algumas espécies consideradas de importância socioeconômica. Nesse caso, o limite entre essas ciências é permeável. Náo se sabe em que ponto exatamente foi "quebrada" a análise com base nos critérios da IUCN, para considerar os critérios das ciências pesqueiras. As declaraçóes do diretor do Departamento de Conservação e Manejo de Espécies do MMA evidenciam essa 
interface. Segundo ele, a instituição chegou à conclusão de que algumas espécies da LVB são passíveis de uso sustentável devido a novos estudos realizados pelos integrantes do GT da Portaria no 445. Esse GT, criado por pressão dos críticos para rever algumas classificações de espécies da lista, representa um interessante exemplo de atuação da ciência regulatória. Nele, técnicos, cientistas pesqueiros e da conservação, empresários e pescadores interagem com agentes governamentais para, juntos, reavaliarem o estado de conservação de organismos aquáticos. A definição de quais são as espécies passíveis de reavaliação foi negociada no GT.

Assim, questôes aparentemente técnicas sobre como medir o estado de conservação de espécies estão ligadas a ideias concorrentes de como a fauna aquática de interesse socioeconômico deve ser gerenciada na esfera política. O depoimento de um cientista da pesca e ex-membro do MPA detalha a existência, no Brasil, de "duas linhas filosóficas", cada uma trabalhando com modelagens diferentes para avaliar os mesmos organismos. Existe uma disputa de fundo sobre como medir as populaçóes de organismos marinhos, que define se elas caem em uma ou outra categoria de conservação passível de uso ou não. Neste caso, a definição de quais serão os indicadores válidos para se chegar à "verdade útil" mais adequada - a inclusão das espécies em categorias de ameaça de extinção mais ou menos rigorosas - para os propósitos políticos que se deseja alcançar - a gestão do uso sustentável - não é uma questão exclusivamente técnica. Aqui, análises científicas locais e internacionais se mesclam com interesses, disputas políticas e valores socioculturais (preservar o meio ambiente ou os pescadores) para coproduzirem avaliaçóes de estado de conservaçáo nacionais.

Questóes de valor e interesse desse tipo têm atravessado debates acadêmicos transnacionais sobre a interface entre conservação e uso sustentável. No que se refere à conservação da fauna marinha, as tensôes não se limitam a disputas entre ciências da conservação e pesqueiras. Ambos os domínios do conhecimento possuem controvérsias internas. Por exemplo, nas ciências pesqueiras, especialistas dividem opiniōes sobre o uso dos diagnósticos e avaliaçóes da FAO para orientar políticas localizadas de gestáo da pesca marinha extrativa. A controvérsia tem como vetor principal as interpretaçóes que resultam da metodologia empregada por essa agência para inferir o estado de conservação dos estoques mundiais e polariza-se em torno 
de dois grupos de pesquisadores que divergem sobre como interpretar a abundância da fauna marinha nas últimas décadas (PAULY; HILBORN; BRANCH, 2013).

Em um grupo, alinham-se cientistas pesqueiros que assumem que os dados de captura da FAO refletem o grau de abundância dos estoques, os quais devem, portanto, ser utilizados para avaliar a saúde dos estoques pesqueiros. Para esses, a maioria dos dados da agência está, inclusive, subdimensionada e a situação é ainda mais crítica do que aquela diagnosticada (PAULY; ZELLER, 2016). Em outro grupo, alinham-se aqueles que defendem que o volume de peixes capturados não reflete, necessariamente, o número de peixes presentes no mar e aos dados de captura devem, necessariamente, ser agregadas informaçóes mais detalhadas e precisas para a elaboração de diagnósticos. Para estes, aceitar que avaliaçóes baseadas exclusivamente em dados de captura orientem políticas públicas de controle da pesca é uma postura apoiada mais em valores e interesses, neste caso à preservaçáo ambiental, do que em dados científicos. O resultado desses diagnósticos, alegam, é o fortalecimento de um padrão de opinião que supôe que a única solução para a conservação marinha é a interdição das pescarias (HILBORN; HILBORN, 2012). Outros trabalhos discutem a linha difusa entre ciência e defesa ambiental entre pesquisadores da conservação consultores da IUCN. De um lado, cientistas repreendem seus pares por se deixarem influenciar por interesses ambientalistas nas avaliaçóes sobre o estado de conservação de populaçôes-alvo de interesse comercial. De outro, esses cientistas se defendem, acusando os colegas de acríticos por náo considerarem os efeitos adversos de suas avaliaçóes (ou abstençóes) e estarem contribuindo com o comércio de espécies selvagens ameaçadas (CAMPBELL, 2002; MROSOVSKY, 2000; WEBB, 2008). Para Campbell (2002), essa última crítica sugere uma tendência "não científica" entre especialistas da IUCN no sentido de forçar uma narrativa de crise naquilo que vem sendo chamado por eles de guerra da conservaçáo.

No Brasil, esses debates refletem diferentes abordagens sobre a gestão do uso sustentável dos recursos pesqueiros. Os depoimentos de entrevistados nesta pesquisa demonstram a presença de duas posiçóes discordantes. Um grupo de especialistas acredita no fracasso da gestão da pesca extrativa baseada em modelagens e indicadores das ciências pesqueiras e aposta 
no emprego de métodos das ciências da conservação como instrumento central para apoiar políticas públicas de reconstrução dos ecossistemas marinhos. Muitos desses especialistas veem o estabelecimento de proibiçóes de pesca como a única maneira de proteger a biodiversidade. Já os especialistas que trabalham em agências de pesca e muitos cientistas acadêmicos concebem um quadro mais dinâmico, com muitas pescarias fracassadas, mas também numerosas possibilidades de êxito. Este grupo argumenta que é necessário aplicar as liçôes das práticas institucionais de gestão pesqueira de sucesso para bloquear o declínio e reconstruir as pescarias ameaçadas pela sobrepesca.

Essas duas visóes e as práticas correlatas, entretanto, são coproduzidas entre espaços transnacionais de discussão e arenas nacionais. As avaliaçóes de estado de conservação obtidas a partir de dados científicos são flexíveis e sensíveis à influência de interesses e valores que vão além da objetividade e neutralidade científica. As "verdades úteis" não são livres de controvérsias e, por definição, elas servem a propósitos (JASANOFF, 2011).

Definir quais são esses propósitos tampouco é uma tarefa unívoca, pontual e permanente. No caso brasileiro aqui analisado, os propósitos ainda estáo sendo definidos, as disputas entre essas duas visôes ainda estão em curso e o processo de consolidação de uma agenda de gestão pública da biodiversidade marinha está em plena construção. Isso é o que nos mostram as negociaçóes em vigor no GT Portaria no 445 para liberação do uso sustentável de algumas espécies descritas na Lista Nacional Oficial de Espécies da Fauna Ameaçadas de Extinção - Peixes e Invertebrados Aquáticos.

\section{Considerações finais}

A análise dos argumentos de críticos e apoiadores da Portaria no 445 a partir do enfoque dos ESC aplicados ao entendimento da ciência regulatória permitiu destacar a influência de controvérsias tecnocientíficas sobre a relação entre uso sustentável e conservação no gerenciamento público brasileiro da biodiversidade marinha e da pesca de base extrativa. De forma complementar, demonstrou o quanto especialistas e agentes governamentais ainda se apoiam na neutralidade da ciência para legitimar seus pontos 
de vista e impugnar aqueles de seus opositores. Embora os participantes invoquem credibilidade científica ao longo das discussôes, há poucos detalhes técnicos discutidos. O debate foi direcionado para registrar ou desacreditar os argumentos de opositores com base em preconceitos e compromissos ideológicos percebidos. Em vez disso, a ciência documentada é contrastada com a defesa de direitos. Alegaçóes de que o "ambientalismo" ou "interesses do setor pesqueiro" influenciavam linhas de argumentação científica divergentes apoiam-se em julgamentos de valor sobre o direito à preservação da natureza per se e à manutenção da pesca extrativa como profissão, respectivamente. Há dois motivos principais que explicam essa imprecisão entre fatos e valores.

Primeiro, a questão da viabilidade do uso sustentável de espécies consideradas ameaçadas permeou todo o debate. Para os defensores da portaria, insinuar que cientistas pesqueiros conselheiros do MPA estavam alinhados com interesses do setor pesqueiro é uma estratégia, certamente, mais fácil do que se engajar em detalhes técnicos de seus argumentos sobre a fragilidade das modelagens e avaliaçóes empregadas pelo MMA. Isso está associado à segunda explicaçáo: a incerteza científica sobre os dados que fundamentaram as avaliaçôes e as implicaçóes que esse fato tem para todos os aspectos da administração marinha. A maior parte dos especialistas concorda sobre a incerteza relativa aos dados brasileiros para fundamentar práticas de gestáo. Assim, existia pouco espaço para os apoiadores da portaria debaterem detalhes técnicos sobre esses dados. Então, a estratégia adotada foi evidenciar os interesses "pesqueiros" daqueles que criticavam a norma. Os críticos tampouco tinham muito espaço para debater cientificamente os dados do MMA, visto que não apresentavam evidências (dados) consistentes contrárias. Aqui, a estratégia consistiu em acusar os apoiadores de "ambientalistas" por só estarem preocupados com a preservação e alheios aos pescadores. Assim, para ambos, foi mais fácil criticar os motivos (interesses) do que os argumentos científicos de seus opositores.

No processo, nem cientistas da conservação nem pesqueiros sentem estar avançando em seu trabalho de aconselhamento. Acusam-se mutuamente por serem capturados por interesses, ao mesmo tempo que alegam não serem ouvidos pelos agentes políticos. Ainda, culpam estes últimos por 
não chegarem a um consenso sobre a melhor forma de gerir recursos aquáticos de importância socioeconômica. Aqui, o conhecimento científico é usado como argumento para purificar a ciência da política e atribuir aos políticos a responsabilidade exclusiva pelo fracasso de suas açóes.

$\mathrm{Na}$ prática, o que se vê não é a exclusão da ciência pelos agentes políticos, mas o descarte de uma corrente em detrimento da outra, seguindo conveniências conjunturais. A Portaria no 445 é mantida em vigor, sinalizando a aceitação, pelas organizaçóes públicas, de práticas conservacionistas de gestão da biodiversidade. Ao mesmo tempo, critérios para definição de viabilidade de uso sustentável para algumas espécies descritas na LVB continuam em debate, sinalizando que o uso sustentável de espécies ameaçadas é possível e desejável. Aqui, as ciências pesqueiras se sobrepóem às da conservaçáo. Isso significa que as definiçôes de verdade sobre o estado de conservação dos peixes não são uma questão exclusiva nem da ciência, nem das políticas. A verdade sobre o estado de conservação desses organismos tem mais a ver com o resultado da interaçáo de diferentes atores, discursos, práticas e interesses do que com a obtenção de números precisos sobre as espécies. A verdade útil sobre o estado de conservação das espécies e práticas de gestão pública da biodiversidade marinha correlatas é, portanto, coproduzida.

Agradecimento: À Coordenação de Aperfeiçoamento de Pessoal de Nível Superior (Capes) - Brasil, que financiou esta pesquisa em sua totalidade.

\section{Referências}

APÓS 30 HORAS atracado em porto, transatlântico Empress deixa píer de Itajaí, no Litoral Norte. O Sol Diário, 6 jan. 2015. Disponível em: https://bit.ly/2Qa6YEe. Acesso em: 23 set. 2016.

BELHABIB, D. et al. Counting pirogues and missing the boat: Reply to Chaboud et al.'s comment on Belhabib et al. "Fisheries catch misreporting and its implications: The case of Senegal". Fisheries Research, v. 164, p. 325-328, abr. 2015.

BELHABIB, D. et al. Fisheries catch misreporting and its implications: The case of Senegal. Fisheries Research, v. 151, p. 1-11, 2014.

BRASIL. Decreto no 6.981/09, de 13 de outubro de 2009. Jusbrasil - Legislação, 2009. 
BRASIL. Instruçáo Normativa no 52, de 08 de novembro de 2005. Brasília, DF, 2005.

CALGARO, F. Após bloqueio em Itajaí, governo admite rever lista de pesca proibida. G1, Brasília, 8 jan. 2015. Disponível em: https://glo.bo/2yaUkhe. Acesso em: 18 ago. 2015.

CAMPBELL, L. Seeing Red: Inside the Science and Politics of the IUCN Red List. Conservation and Society, v. 10, n. 4, p. 367. 2012.

CAMPBELL, L. M. Science and sustainable use: Views of marine turtle conservation experts. Ecological Applications, v. 12, n. 4, p. 1229-1246, 2002.

CAMPBELL, L. M.; GODFREY, M. H. Geo-political genetics: Claiming the commons through species mapping. Geoforum, v. 41, n. 6, p. 897-907, nov. 2010.

CARTA ABERTA à Presidenta Dilma Rousseff. Estadáo, 14 jan. 2015. Disponível em: https://bit. ly/2peiNhR. Acesso em: $12 \mathrm{dez} .2016$.

CHABOUD, C. et al. Comment on "Fisheries catch misreporting and its implications: The case of Senegal”. Fisheries Research, v. 164, p. 322-324, 2015.

COLLEN, B. et al. Clarifying misconceptions of extinction risk assessment with the IUCN Red List. Biology Letters, v. 12, n. 4, p. 20150843, 2016.

CRESSEY, D. Fisheries: Eyes on the ocean. Nature, v. 519, n. 7543, p. 280-282, 2015.

DIAS NETO, J. O uso da biodiversidade aquática no Brasil: uma análise com foco na pesca. Brasília: Ibama, 2015.

ECODEBATE. Entidades e cientistas pedem proteção para 475 espécies aquáticas ameaçadas que podem desaparecer. EcoDebate, 25 jun. 2015. Disponível em: https://bit.ly/2X6O8PQ. Acesso em: 2 out. 2015.

GUERRA, C. Lista de peixes em extinção compromete 50\% do volume pescado em Itajaí e regiáo, diz presidente do Sindipi. O Sol Diário, 6 jan. 2015. Disponível em: https://bit.ly/2X74yrH. Acesso em: 6 jan. 2015.

HALPERN, B. S. et al. An index to assess the health and benefits of the global ocean. Nature, v. 488, n. 7413, p. 615-620, 2012.

HAAS, P. M.; JASANOFF, S. Earthly Politics: Local and Global in Environmental Governance. Massachusetts: The MIT Press Cambridge, 2004.

HACKETT, E. J. et al. The Handbook of Science and Technology Studies. 3th. ed. London: Society for Social Studies of Science, 2008.

HILBORN, R.; HILBORN, U. Overfishing: What Everyone Needs to Know. United Kingdon: Oxford University Press, 2012.

IRWIN, A. STS Perspectives on Scientific Governance. In: HACKETT, E. J. et al. (ed.). The Handbook of Science and Technology Studies. London: Sciety for Social Studies of Science, 2008. p. 583-608. 
A coprodução das ciências e das políticas na gestão da biodiversidade marinha brasileira: a controvérsia sobre o manejo sustentável de espécies ameaçadas | Andreza Martins, Julia Silvia Guivant

IUCN. IUCN Red List categories and criteria: version 3.1. Gland: Switzerland and Cambridge, 2001.

JASANOFF, S. States of Knowledge: The Co-Production of Science and Social Order. London: Routledge, 2004.

JASANOFF, S. Watching the watchers: lessons from the science of science advice. The Guardian, p. online, 18 abr. 2013.

JASANOFF, S. K. S. What is the regulatory science? Concept and history in United States and in Japan: Interview with Professor Sheila Jasanoff, Chieko Kurihara, Takeo Saio. August. Clinical Evaluation, v. 39(1), n. 5, p. 1-16, 2011.

JORNAL NACIONAL. Programa de TV. Rede Globo, 6 jan. 2015. Disponível em: https://glo. bo/2Q9OfsB. Acesso em: 21 set. 2015.

KAISER, M. J. Overfishing: What Everyone Needs to Know. Book Review, v. 82, n. 3, p. 1101 1102, 2013.

LATOUR, B. Ciência em Açáo: como seguir cientistas e engenheiros sociedade a fora. 2. ed. Sáo Paulo: Ed. Unesp, 2011.

LATOUR, B.; WOOLGAR, S. A vida de laboratório: a produção dos fatos científicos. Rio de Janerio: Relume Dumará, 1997.

LAW, J.; SINGLETON, V. Performing Technology's Stories: On Social Constructivism, Performance, and Performativity. Technology and Culture, v. 41, n. 4, p. 765-775, 2000.

LISTAS NACIONAIS de Espécies Ameaçadas de Extinção. Ministério do Meio Ambiente, 2014. Disponível em: https://bit.ly/2Kgyrk9. Acesso em: 30 maio 2019.

MACE, P. A New Role for MSY In Single-Species and Ecosystem \Approaches to Fisheries Stock Assessment and Management. Fish and Fisheries, v. 2, p. 2-32, 2001.

MARRUL FILHO, S. Crise e sustentabilidade no uso dos recursos pesqueiros. Brasília: Ed. Ibama, 2003.

MMA/BRASIL. Proibiçáo de pesca de 15 espécies é adiada para 2018. Disponível em: https:// bit.ly/3b0SUEV. Acesso em: 12 maio 2018.

MMA. Lista Nacional Oficial de Espécies da Fauna Ameaçadas de Extinçáo - Peixes e Invertebrados Aquáticos. Brasília, DF, 2014. Disponível em: https://bit.ly/2xn1LSv. Acesso em: 10 out. 2015.

MOL, A. Ontological Politics. A Word and Some Questions. The Sociological Review, v. 47, n. 1, p. 74-89, 1999.

MROSOVSKY, N. IUCN's credibility critically endangered. Nature, v. 389, n. 6650, p. 436-436, 2 out. 1997. 
MROSOVSKY, N. Sustainable Use of Hawksbill Turtles: Contemporary Issues in Conservation. Darwin: Key Centre for Tropical Wildlife Management, 2000.

NELKIN, D. Controversy: politics of technical decisions. [S. l.]: Sage Publications, 1980.

NEVES, F. P. das. Largando o Ferro. Revista Sindipi, n. 65, p. 7-10, 2015.

OCEANA BRASIL. Sobre nós. 2019. Disponível em: https://brasil.oceana.org/pt-br/sobre-nos. Acesso em: 18 fev. 2019.

PAIVA, M. P. Administraçáo Pesqueira no Brasil. Rio de Janeiro: Interciência, 2004.

PATRICIO, A. M. et al. Pathways for sustainable industrial fisheries in southeaster and southern Brazil. Latin American Journal of Aquatic Research, v. 44, p. 875-881, 2016.

PAULY, D.; HILBORN, R.; BRANCH, T. A. Does catch reflect abundance. Nature, v. 494, p. 3-6, 2013.

PAULY, D.; ZELLER, D. Catch reconstructions reveal that global marine fisheries catches are higher than reported and declining. Nature, v. 7, p. 10244, 2016.

PIO, V. M.; PEZZUTO, P. R.; WAHRLICH, R. Only two fisheries? Characteristics of the industrial bottom gillnet fisheries in southern Brazil and their implications for management. Latin American Journal of Aquatic Research, v. 44, p. 882-897, 2016.

PRESOTTI, C. Cientistas e organizações pedem proteção para 475 espécies ameaçadas de extinção. Portal de Políticas Socioambientais, 25 jun. 2015.

PROIBIÇÃO DE PESCA de 15 espécies é adiada para 2018, Agência Brasil, 23 dez. 2017. Disponível em: https://bit.ly/2CBPDMq. Acesso em: 12 maio 2018.

QUEIROZ, N. et al. Global spatial risk assessment of sharks under the footprint of fisheries. Nature, p. 1-27, 2019.

REUNIÓES GT 445. Oceana Brasil - Canal Youtube. 201-. Disponível em: https://bit. ly/3b1f9dV. Acesso em: 19 mar. 2018.

RICHARDSON, P. Obstacles to Objectivity: First Impressions of a CITES CoP. Marine Turtle Newsletter, n. 89, p. 1-7, 2000.

RODRIGUES, A. S. L. et al. The value of the IUCN Red List for conservation. Trends in Ecology and Evolution, v. 21, n. 2, p. 71-76, 2006.

ROSENBERG, A. A. et al. Developing New Approaches to Global Stock Status Assessment and Fishery Production Potential of The Seas. FAO Fisheries and Aquaculture Circular, Rome: FAO, n. 1086, 2014.

SALTER, L.; LEVY, E.; LEISS, W. Mandated Science: Science and Scientists in the Making of Standards. Dordebrecht: Kluwer Academic Publishers, 1988. 
A coprodução das ciências e das políticas na gestão da biodiversidade marinha brasileira: a controvérsia sobre o manejo sustentável de espécies ameaçadas | Andreza Martins, Julia Silvia Guivant

SISMONDO, S. Science and Technology Studies and an Engaged Program. In: HACKETT, E. J. et al. (ed.). The Handbook of Science and Technology Studies. London: Society for Social Studies of Science, 2008. p. 13-31.

SOULÉ, M. E. What is Conservation Biology. A New Synthetic Discipline Addres The Dynamics and Problems of Perturbed Species, Communities and Ecosystems. BioScience, v. 35, n. 11, p. 727-734, 1985.

TURNER, R. S. On telling regulatory tales: rBST comes to Canada. Social Studies of Science, v. 31, n. 4, p. 475-506, 2001.

WEBB, G. J. W. The dilemma of accuracy in IUCN Red List categories, as exemplified by hawksbill turtles Eretmochelys imbricata. Endangered Species Research, v. 6, p. 161-172, 2008.

WORM, B. et al. Rebuilding global fisheries. Science (New York, N.Y.), v. 325, n. 5940, p. 578$585,2009$.

YEARLEY, S. Nature and the Environment in Science and Technology Studies. In: HACKETT, E. J. et al. (ed.). The Handbook of Science and Technology Studies. London: Society for Social Studies of Science, 2008. p. 921-948.

Recebido 10/04/2020

Aprovado 15/04/2020 


\title{
The Science and Policy Coproduction in Brazilian Marine Biodiversity Management: the endangered species sustainable management controversy
}

\begin{abstract}
The threatened species sustainable use is at the center of international technoscientific controversies that discuss the role of science in guiding marine conservation policies. In Brazil, these controversies had an impact on institutional disputes over the best way to measure, evaluate and manage fishery resources. The disputes permeated political negotiations to reverse fishing bans on dozens of species included in the National List of Endangered Species. From Social Studies of Science perspective, we discussed the expert knowledge influence in the political negotiations involved in the case. Analyzing arguments from the measure critics and supporters, we understand that in Brazil scientific uncertainties about aquatic fauna conservation status result in divergent public management practices acting on the same spaces and resources. Such practices combine competing views on how public administration should deal with scientific uncertainty and coproduce policies for managing marine biodiversity.
\end{abstract}

Keywords: Social Science Studies. Regulatory science. Marine governance. Coproduction. 